\title{
Prevalence of patent ductus arteriosus in premature infants at the Neonatal Ward, Cipto Mangunkusumo Hospital, Jakarta
}

\author{
Benita Deselina, MD; Sukman Tulus Putra, MD; Rulina Suradi, MD
}

\begin{abstract}
Background Patent ductus arterious (PDA) is one of the most common congenital heart diseases encountered in preterm infants. The lower the birth weight and gestational age are, the higher the incidence of PDA is.

Objectives To investigate the incidence of PDA in premature infants hospitalized in the neonatal wards of Cipto Mangunkusumo Hospital using echocardiography.

Methods Preterm infants born between August and October 2003 were included in this study. Clinical features were retrieved from medical charts. The first echocardiography was conducted on all of the preterm infants at the chronological age of 3 days. If PDA was detected, echocardiography was repeated at the chronological age of 6 days.

Results During the 3-month period, sixty-five preterm infants participated in this study and underwent echocardiography. In the first echocardiogram, the incidence rate of PDA was $32 \%$. At gestational age of less than 28 weeks, 1 of 2 infants had PDA. Of 3 infants with birth weight of more than 1000 grams, 2 had PDA. On the second echocardiography, the incidence rate of PDA was $14 \%$ and mostly found in infants at gestational age of less than 28 weeks (8/9) and in those with birth weight of less than 1000 grams (7/9). All infants with RDS whose PDA was identified in the first echocardiography proved to maintain their PDA in the second echocardiography.

Conclusion The incidence rate of PDA in preterm infants was $14 \%$. The lower the birth weight, the higher the incidence rate of PDA. The presence of RDS is related to the delay in the closing of the arterial duct [Paediatr Indones 2004;44:223-227].
\end{abstract}

Keywords: preterm infant, patent ductus arteriosus, incidence, echocardiography.

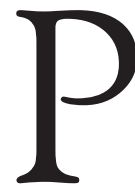

hysiologically, functional closing of ductus arteriosus occurs within 2 until 4 days after birth. ${ }^{1-4}$ The ductal shunting that persists for more than 4 days is a pathological condition in healthy preterm infants. ${ }^{5}$ Conditions that can contribute to the delay of the closing of ductus arteriosus are asphyxia, respiratory distress syndrome (RDS), low birth weight, and prematurity. $1,2,6,7$ Preterm infants with RDS have a higher risk for the development of PDA.3,8-10 The prevalence rate of PDA in preterm infants with RDS varies between $15-35 \%$ in infants whose birth weight are less than 1800 grams and $50-85 \%$ in those with birth weight less than 1200 grams. $^{7}$ In addition, low birth weight and prematurity predispose the prevalence rate of PDA to rise. ${ }^{2,8,10}$ It could be attributed to the fact that the immature ductus is more sensitive to the vasodilating effects of prostaglandin and decreased sensitivity of the premature ductus to ductal constrictors, especially to oxygen. ${ }^{1}$ The result of a collaborative trial, showed that the prevalence rate of PDA in preterm infants was $20.2 \%$ and it was evident that infants with low birth weight had higher prevalence rate of PDA, i.e., $42 \%$ in infants whose birth weight less than 1000 grams, $20.6 \%$ in those with birth weight

From the Department of Child Health, Medical School, Universiy of Indonesia, Jakarta, Indonesia.

Reprint requests to: Sukman T Putra, MD, Department of Child Health, Medical School, University of Indonesia, Jakarta, Jalan Salemba 6, Jakarta 10430, Indonesia, Tel.62-21-3907742, email: stpfile@dnet.net.id 
1000-1499 grams and 7\% in those with birth weight more than 1500 grams. ${ }^{11}$ On the other hand, born to mothers who were on prenatal corticosteroids, the prevalence rate of PDA in preterm infants was lower. ${ }^{2,12}$ This condition could be attributed to the fact that corticosteroids can reduce sensitivity to the dilating effect of prostaglandin and they are indirectly correlated with the maturation effect of the lungs. ${ }^{10}$

Diagnosis of PDA can be clinically established and confirmed with the use of color Doppler echocardiograph. ${ }^{13-15}$ This kind of examination does not cause pain and is quite safe especially for neonates with poor general condition.

In our department, there is no data on the prevalence rate of PDA in preterm babies. The purpose of this study was to find out the prevalence rate of PDA in preterm infants born in Cipto Mangunkusumo General Hospital.

\section{Methods}

A prospective cross sectional study was carried out on neonates born in Cipto Mangunkusumo Hospital during the period of August 2003 to October 2003, at a gestational age of less than 37 weeks. The babies were hospitalized in our neonatal ward for one week. Gestational age was determined according to the New Ballard Score ${ }^{16}$ and approved by the supervisor of the ward. The patients' data were obtained consecutively from the neonatal ward, Cipto Mangunkusumo Hospital. Infants were excluded from the study if they had: (1) evidence of congenital malformation including congenital heart disease other than PDA; (2) parent's refusal to participate in the trial. The study was already approved by The Committee of the Medical Research Ethics of the Medical School, University of Indonesia and parental consent was obtained for each case. Sixtyfive infants met these criteria. Neonates that were already included as subjects underwent echocardiography.

The echocardiographic examinations were done using Sonos model 4500 color flow ultrasound imaging system. The 2-dimensional images and color flow doppler signals were obtained with a $7.5 \mathrm{MHz}$ short-focus transducer.
Echocardiography was performed at days 1-4 by the same pediatric cardiology consultant. The reading of the results was conducted at the same time and the results were recorded on VHS tape.

Patients with PDA underwent a repeated echocardiography at day 5-8 to evaluate the closing of ductus arterious. PDA lesions were catagorized into small ductal shunting if the diameter of the duct was $<1.5 \mathrm{~mm}$ and moderate if the diameter was $1.5-2$ $\mathrm{mm}$ and large if the diameter exceeded $>2 \mathrm{~mm}$.

The medical charts of infants were reviewed for the following characteristics: Birth weight less than 2500 grams, 1- and 5-minute Apgar scores, respiratory distress syndrome, prenatal dexamethasone given at least 24 hours before delivery.

\section{Results}

\section{Subjects' characteristics}

During that period, 85 preterm infants hospitalized in the neonatal wards, but 20 neonates could not be enrolled into the study because 14 infants died before the echocardiography had been done and 6 parents refused to include their infants into the trial. Totally, only 65 preterm infants participated in this study.

Tabel 1. Clinical characteristics

\begin{tabular}{llc}
\hline Characteristics & $\mathbf{n}$ \\
\hline Gestational age & $<32$ weeks & 18 \\
& $32-36$ weeks & 47 \\
Birthweight & $<1500$ grams & 18 \\
& $1500-2499$ grams & 47 \\
Sex & Male & 33 \\
& Female & 32 \\
Asphyxia at minute 5 & Yes & 11 \\
& No & 54 \\
RDS & Yes & 10 \\
Antenatal dexamethasonee & No & 55 \\
& Yes & 23 \\
Delivery & No & 42 \\
& Spontaneous & 33 \\
& Cesarian section & 29 \\
& Vaccum extraction & 3 \\
\hline
\end{tabular}

\section{Echocardiographic examination}

The first echocardiographic examination was performed on all of the preterm infants at the chronological age between 1 and 4 days, a mean of 3 days. Patent ductus arteriosus was encountered in 21 infants (32\%), with a small shunting encountered in 6 infants, a moderate shunting in 3 infants, and a large shunting in 12 infants. 
Table 2. Correlation between the subjects' characteristics and PDA on the first ECHOCARDIOGRAPHIC EXAMINATION

\begin{tabular}{llccc}
\hline Subject characteristic & & $\begin{array}{c}\text { PDA (+) } \\
\mathbf{n}\end{array}$ & $\begin{array}{c}\text { PDA (-) } \\
\mathbf{n}\end{array}$ & $\begin{array}{c}\text { Total } \\
\mathbf{n}\end{array}$ \\
\hline Sex & Male & 8 & 25 & 33 \\
Asphyxia & Female & 13 & 19 & 32 \\
RDS & Yes & 7 & 4 & 11 \\
& No & 14 & 40 & 54 \\
Gestational age & Yes & 6 & 4 & 10 \\
& No & 15 & 40 & 55 \\
Birthweight & $<28$ weeks & 1 & 1 & 2 \\
& $28-31$ weeks & 9 & 7 & 16 \\
\multirow{2}{*}{ Prenatal dexamethasone } & $32-36$ weeks & 11 & 36 & 47 \\
& $<1000$ grams & 2 & 1 & 3 \\
& $1000-1499$ grams & 8 & 7 & 15 \\
& $1500-2500$ grams & 11 & 36 & 47 \\
& Yes & 8 & 15 & 23 \\
& No & 13 & 29 & 42 \\
\hline
\end{tabular}

The second echocardiographic examination was performed at the chronological age between 5 and 8 days, at a mean of 6 days. Only 17 infants underwent the second echocardiography because 4 infants died before IT WAS done. PDA was identified in 5 infants (8\%). If the 4 infants who died was considered as suffering from PDA in the second echocardiographic examination, the prevalence rate of PDA would be $14 \%(9 / 65)$. On the second echocardiographic examination, of 6 infants whose previous echo examination showed a small duct, 5 revealed closing of the shunt and 1 had persistent small ductal shunting; 3 infants with moderate shunting, 1 experienced closing of the shunt, 1 experienced a reduction in shunt and the other one died before the second echocardiography. Among 9 infants with large shunting, 3 the shunt remained large and was subsequently closed in 6 , and the remaining 3 died before echocardiography reevaluation was performed.

Table 2 shows that among 11 infants with asphyxia, there were 7 infants with PDA. PDA was also found in 6 of 10 infants with respiratory distress syndrome. The most common characteristics found in this study were gestational age of 28-31 weeks (9 of 16 patients) and birthweight of less than 1000 grams (2 of 3 patients).

Table 3 shows that 5 of 9 infants who had PDA had asphyxia at birth, 6 of 9 infants had RDS. It showed that the lower the gestational age and birth weight were, the higher the prevalence of PDA was. In gestational period of less than 28 weeks, PDA was found in 1 of 2 infants; in gestational period of 28-31 weeks was 6 of 16 , and 2 of 47 in 32-36 weeks.

Table 3. Correlation between subjects' characteristics and PDA on the second ECHOCARDIOGRAPHIC EXAMINATION

\begin{tabular}{llccc}
\hline Subject characteristic & & PDA (+) & $\begin{array}{c}\text { PDA (-) } \\
\mathbf{n}\end{array}$ & $\begin{array}{c}\text { Total } \\
\mathbf{n}\end{array}$ \\
\hline Sex & Male & 5 & 28 & 33 \\
& Female & 4 & 28 & 32 \\
Asphyxia & Yes & 5 & 6 & 11 \\
RDS & No & 4 & 50 & 54 \\
Gestational age & Yes & 6 & 4 & 10 \\
& No & 3 & 52 & 55 \\
Birthweight & $<28$ weeks & 1 & 1 & 2 \\
& $28-31$ weeks & 6 & 10 & 16 \\
\multirow{3}{*}{ Prenatal dexamethasone } & $32-36$ weeks & 2 & 45 & 47 \\
& $<1000$ grams & 2 & 1 & 3 \\
& $1000-1499$ grams & 5 & 10 & 15 \\
& $1500-2500$ grams & 2 & 45 & 47 \\
& Yes & 4 & 19 & 23 \\
& No & 5 & 37 & 42 \\
\hline
\end{tabular}


It was also noted that PDA was encountered in 2 of 3 infants with birthweight of $<1000$ grams, and 5 of 15 with the birth weight of 1000-1499 grams, 2 of 47 with 1500-2500 grams.

\section{Discussion}

Echocardiographic examination is a non-invasive tool to diagnose PDA in preterm infants.. ${ }^{17-19}$ Some investigators have stated that the pattern of the ductal shunting flow that could be seen during the echocardiographic examination for the first 4 days of birth can be used to predict the significant progression of PDA in preterm infants. $3,13,20$

In this study, the echocardiographic examination was in accordance with the literature, being performed at the mean chronological age of 3 days (the earliest at 1 day and the latest at day 4).

The prevalence rate of PDA in the first echocardiographic examination was $32 \%(21 / 65)$ or the closure rate of the ductus was $68 \%$ (44/65). Compared to the results of a trial by Evans et al (closure rate was $95 \%$ ) or by Reller et al, ${ }^{8}$ (closure rate was $90 \%$ ), the closing rate in this trial was significantly lower. It was attributed to the fact that in their study, the results of the echocardiographic examination were the final outcomes of serial echocardiographic examinations at day 4, whereas in this studies echocardiography was only performed once on each subject with various time from day 1 to day 4 .

On the second echocardiographic examination, the prevalence rate of PDA was $14 \%$, higher than that reported by Reller et al20 (4.2\%) and by Evans et $a^{5}$ (5\%). This was caused by the differences in designs and subject population. In this study, the subjects were all preterm infants whereas in the comparative literature, the subjects were healthy preterm infants. However, although echocardiography was performed on all preterms, the prevalence of PDA of this study was lower than those of Ellison et al $(20.2 \%)^{11}$ and Siassy et al (21\%). ${ }^{21}$ It could be attributed to their larger sample size and longer duration of study.

In Table 2, 6 preterm infants ( 5 infants with birth weight of $<1500$ grams) with RDS had PDA on the first echocardiography. On the second echocardiography, all of those infants (100\%) still had persistence of the duct. These were in accordance with those of Skinner $^{3}$ and Reller et al ${ }^{20,22}$ showing that in preterm infants, RDS could cause a delay in the physiological closure of the ductus. Hammerman ${ }^{23}$ found the prevalence rate of PDA in preterm infants with RDS with weight of $<1200$ grams was $80 \%$.

Seven infants with asphyxia at birth suffered from PDA as found on the first echocardiography and only 2 infants whose ductus arteriosus closed as seen on the second echocardiography. It was in accordance with the study of Reller et al ${ }^{8}$ who stated that asphyxia can lead to a delay in closure of the duct. This condition was also in accordance with some literature stating that asphyxia gives a risk for hypoxia resulting in persistent duct.6,8,10

Some literature reported that prenatal corticosteroid administration can reduce the prevalence of PDA. ${ }^{4,11}$ Table 3 shows that in 42 infants whose mothers did not receive prenatal dexamethasone, 5 of 42 infants suffered from PDA. This result was lower than that reported by Waffarn et al. ${ }^{24}$ It was caused by the fact that in this study, not all of the subjects' mothers received corticosteroids prior to delivery.

The prevalence rate of PDA was very high in infants with low gestational age and birthweight. This condition was in accordance with the literature that the lower the gestational age and birthweight, the higher the prevalence rate of PDA.8,2,10 The result of this trial was almost similar to that of Ellison et al. ${ }^{11}$ However, the results of this trial were lower than those of Siassy et al. ${ }^{21}$ In their studies, the sample size was larger and the duration of observation was longer.

In conclusion, the prevalence rate of PDA in preterm infants detected the first echocardiography at the mean chronological age of 3 days was 32\%. On the second examination at the mean age of 6 days the prevalence of PDA was $14 \%$. The lower the birth weight and gestational age, the higher the prevalence rate of PDA. Respiratory distress syndrome is related to the delay in the closure of ductus arteriosus.

\section{References}

1. Clyman RI. Ibuprofen and patent ductus arteriosus. N Eng J Med 2000;343:728-9. 
2. Archer N. Patent ductus arteriosus in the newborn. Arch Dis Child 1993;69:529-32.

3. Skinner J. Diagnosis of patient ductus arteriosus. Semin Neonatal 2001;6:49-61.

4. Lim MK. Hanretty K. Houston AB, Lilley S. Intermittent ductal patency in healthy newborn infants: demonstration by colour-Doppler flow mapping. Arch Dis Child 1992;67:1217-8.

5. Evans NJ, Arcer NJ. Postnatal circulatory adaptation in healthy term and preterm neonates. Arc Dis Child 1990;65:24-6.

6. Mullins CE. Patent ductus arteriosus. In: Garson A, Bricker JT, McNamar DG, editors. The science and practice of pediatric cardiology. 2nd ed. Philadelphia: Lea and Febiger; 1990. p.1055-72

7. Reller MD, Colasurdo Ma, Rice MJ. The timing of spontaneous closure of the ductus arteriosus in infants with respiratory distress syndrome. Am J Cardiol 1990;25:75-66.

8. Reller MD, Rice GM. Mc.Donald RW. Review of studies evaluating ductal patency in premature infant. J Pediatr 1993;22(Suppl):59-62.

9. Jones RW, Pickering D. Persistent ductus arteriosus complicating the respiratory distress syndrome. Arch Dis Child 1977;52:274-81.

10. Knight DB. The treatment of patent ductus arteriosus in preterm infants. A review and overview of randomized trials. Semin neonatal 2001;6:63-73.

11. Ellison RC, Peckham GJ, Lang P. Evaluation of the preterm infant of patent ductus arteriosus. Pediatrics 1983;71:364-72.

12. Eronem M. The effect of antenatal dexamethasone administration of the fetal and neonatal ductus arteriosus. A randomized double blind study. Am J Dis Child 1993;147;187-92.

13. Kluckow M, Evans N. Early echocardiographic prediction of symtomatic patent ductus arteriosus in preterm infants undergoing mechanical ventilation. J Pediatr 1995;127:774-9.
14. Roberson DA, Silverman NH. Color Doppler flow mapping of the patent ductus arteriosus in very low birth weight neonatus: echocardiographic and clinical findings. Pediatr cardiol 1994;15: 219-24.

15. Evans N. Diagnosis of patent ductus arteriosus in the preterm newborn. Arch dis Child 1993;68: 58-61.

16. Ballard JL, Khoury JC, Wedig K, Wang L. New Ballard Score, expanded to include extremely premature infants. J Pediatr 1991;119:417-23

17. Sastroasmoro S. Dasar diagnosis dan tatalaksana penyakit jantung bawaan. Jakarta: Perhimpunan Kardiologi Anak Indonesia; 1998. p. 3-40.

18. Brook MM, Heymann MA. Patent ductus arteriosus.In: Pine JW, Moss and Adams M,editors. Heart disease in infants, children and adolescent. Baltimore: Williams and Wilkins; 1995. p. 746-64.

19. Musewe NN, Olley PM. Patent ductus arteriosus. In: Freedom RM, Benson LN, Smallhom JF, editors. Neonatal Heart Diseases. London: Springer-verlag; 1992. p. 593-607.

20. Reller MD, Ziegler ML, Rice MJ. Duration of ductal shunting in healty preterm infants: an echocardiographic color flow Doppler study. J Pediatr 1988;112:441-6.

21. Siassy B, Blanco C, Coran AG. Incidence and clinical features of PDA in low birth weight infants: a prospective analysis of 150 consecutively born infants. Pediatrics 1976;57:347-51.

22. Reller MD, Laird MR, Rice MJ. Timing of ductal closure in very low birth weight premature infants without respiratory distress. J Pediatr 1991;119:976-7.

23. Hammerman C. Patent ductus arteriosus: clinical prevalence of prostaglandin inhibitor in PDA pathophysiology and treatment. In: Caplan MS. Hageman JR, editors. Clinics in perinatalogy. Philadelphia: WB Saunders; 1995. p. 457-79.

24. Waffarn F, Siassi B, Cobal LA. Effect of antenatal glucocorticoids of clinical closure of the ductus arteriosus. Am J Dis Child 1983;37:336-8. 